\title{
Geomorphologic Domination on Urban Sprawl of Southern Riyadh, Saudi Arabia Using Differential Interferometric Synthetic Aperture Radar (DInSAR)
}

\author{
Mohamed Daoudi1 ${ }^{*}$, Kamel Hachemi², Abdullah O. Bamousa ${ }^{3}$ \\ ${ }^{1}$ Department of Geography and GIS, Faculty of Arts and Humanities, King Abdulaziz University, Jeddah, Saudi Arabia \\ ${ }^{2}$ Physical Geography Laboratory (LGP), UMR 8591, CNRS, University Paris-1 and University Paris-Est, 1 place Aristide Briand, \\ Meudon Cedex, France \\ ${ }^{3}$ Department of Geology, Faculty of Sciences, Taibah University, Al-Madinah Al-Munawarah, Saudi Arabia \\ Email: ^mdaoudi@kau.edu.sa
}

How to cite this paper: Daoudi, M., Hachemi, K. and Bamousa, A.O. (2021) Geomorphologic Domination on Urban Sprawl of Southern Riyadh, Saudi Arabia Using Differential Interferometric Synthetic Aperture Radar (DInSAR). International Journal of Geosciences, 12, 541-559.

https://doi.org/10.4236/ijg.2021.126030

Received: May 3, 2021

Accepted: June 14, 2021

Published: June 17, 2021

Copyright $\odot 2021$ by author(s) and Scientific Research Publishing Inc. This work is licensed under the Creative Commons Attribution International License (CC BY 4.0).

http://creativecommons.org/licenses/by/4.0/

(c) (i) Open Access

\begin{abstract}
This study tests the southern part of the Riyadh City growth domination by the Early Quaternary-Holocene trans-tensional Central Arabian graben system reactivation and the subsequent dissolution-induced collapses and karstification. This study utilizes Synthetic Aperture Radar (SAR) and Differential Interferometric Synthetic Aperture Radar (DinSAR) to examine the morphology of arid landscape, south of Riyadh. Eight Single Look Complex (SLC) amplitude images are calibrated, filtered, georeferenced and orthorectified at a resolution of 20 meters, and compared with one another by producing 17 diachronic images of the pairs at different intervals $(1996,2003-2005,2008)$. The diachronic SAR intensity imageries suggest a downthrown displacement reaching $600 \mathrm{~m}$ and eastward tilting at the bottoms of the grabens. Also, the structurally-controlled valleys are developing an eastward-running drainage system towards the oasis of Al-Kharj and capturing an older hydrologic system. Moreover, a 12-year period (1996-2008) of the SAR data was obtained to examine the average annual rate of southern Riyadh's urban sprawl, which is estimated at approximately 390 metres/year over the 12 years and constrained by geomorphological features towards the deformed area. DInSAR imageries show the primary results obtained from the 26 May 2004 and 31 Jan. 2005 pair of images, merged with $30 \mathrm{~m}$ resolution DEM-SRTM data for the arid region south of Riyadh to eliminate the influence of topography. DInSAR is applied in this study for its ability to detect small displacements at the centimetre scale ( $1 / 2$ wavelength). Although the DInSAR's coherence and phase imageries suggest a fairly stable region since the last tectonic and subsequent
\end{abstract}


geomorphic events, erosional and artificial changes are observed, bounded within the valleys and depressions, primarily due to aeolian and fluvial processes and agriculture. It is highly recommended to preserve the area for sustainability and economy.

\section{Keywords}

Landscape Morphology, SAR, DInSAR, Wadi Awsat, Wadi Nisah, Riyadh City

\section{Introduction}

This study tests the ability of recent techniques and methodology to create shortperiod monitoring and analyses via available SAR and DInSAR images. It utilises these data to summarise the natural and artificial evolution and changes that had occurred in different areas such as those during a period of almost 12 years. The radar data are provided with colour composition (diachronic) images that represent a 12-year period for monitoring potential hazardous features witnessing several constructions that have multiplied on the periphery of and outside the city of Riyadh. This study tests the ability of the SAR and DInSAR imageries and applies them on arid region for the reported karstification (e.g. [1] and recent activities of the Sahba fault and valley, to the east of Al-Kharj [2]. Very little detailed work was carried out on the study area using the radar, for example, shuttle radar images have been used to detect several geological features in the Arabian Peninsula [3], aeolian sand covers [4] and faults and landslides under the Quaternary sands of the Ad-Dahna Desert [2]. In the field of cartography, [5] showed the usefulness of the interpretation of SAR imagery from the Radarsat-1 satellite in mapping applications in Riyadh. Another regional study was conducted by [6] on the integration of multispectral and radar images for geological, geomorphic, and structural study in the Al Qunfudhah region. An additional study by [7] employed optical and radar images for the identification and monitoring of active/inactive landforms in the driest desert of Saudi Arabia.

Radar images have the advantage of being taken in all weather conditions, day, and night, and regardless of cloud cover, unlike platforms that operate within the visible range. The use of satellite radar imagery allows for regular and precise spatial and temporal monitoring of surfaces. The response of the radar signal is particularly sensitive to surface topography, roughness, and moisture, making it possible to determine any natural or artificial changes that occur between two image acquisitions. Synthetic-aperture radar (SAR) is a form of radar that is used to create two- or three-dimensional landscape images. It provides large image coverage $(100 \mathrm{~km} \times 100 \mathrm{~km})$ for both generalised and global studies of regions. SAR sensors measure the two components of the backscattered signal, amplitude and phase, where phase (waves) depends on geometrical characteristics, such as distance information between the radar and the target. Phase cor- 
responds to the temporal distance between the radar sensor and the target. In this regard, it is used in estimating displacement in interferometric applications; this allows for measuring vertical and horizontal displacements in the order of $1 / 2$ wavelength. The amplitude of an image pixel represents the backscattering capability of the terrain of the corresponding ground pixel to send the incident energy back to the antenna [8]. It is directly usable and comparable to the optical image, and is also directly related to the surface conditions, thus, some surfaces are represented by a high radiometric value, whereas dry and water surfaces appear with low radiometric values. SAR images have wide application in remote sensing and geological and environmental studies of arid and semi-arid lands [9]-[18]. Differential interferometric synthetic-aperture radar (DInSAR) uses two or more SAR satellite images to generate maps of surface deformation or digital elevation, using differences in the phase of the waves returning to the satellite (e.g. [19]). This makes it possible to measure vertical ground displacements up to $28 \mathrm{~mm}$ in the case of the C-band, when each fringe is multiplied by $28 \mathrm{~mm}$. DInSAR can yield significant results between two different dates in the same area; one can measure the extensive, precise, and dense ground changes that occur between these two periods.

The main aim of this study is to test the hypothesis of urban sprawl domination by active trans-tensional tectonism and subsequent karstification during the Quaternary Era, in southern Riyadh. The ultimate objective of this work is to alert the community and preserve the area over the south of Riyadh and east of Al-Kharj, in Central Saudi Arabia, for future water and food security, for economic aspects, and as a national geopark for scientific research and tourism.

\section{Study Area}

Desert, semi-arid, and degraded land areas are considered arid regions, despite the presence of irrigated vegetation and oasis areas [20]. The Central Arabia, south of Riyadh, between latitudes $24^{\circ}-25^{\circ} \mathrm{N}$ and longitudes $46^{\circ}-47^{\circ} \mathrm{E}$ has similar conditions, in that it is occupied by an oasis, known as the Al-Kharj oasis, and wadi of Nisah-Sahaba grabens, surrounded and influenced by the Ad-Dahna desert [2]. The abundant groundwater and seasonal hydrological water enhanced the feasibility of circular irrigated farms, accommodated by the depressions and grabens, to the west of the Al-Kharj oasis (Figure 1). The region has a dry tropical climate, characterised by high temperatures in summer, cold temperatures in winter, rainfall scarcity and irregularities, high evaporation rates that exceed precipitation rates, and low relative humidity. The morphology of the landscape is occupied by the Tuwaiq Mountain plateaus, south of Riyadh (Central Arabia), steeply cut, incised, and stepped over the Wadi Nisah and Wadi Sahaba grabens. Therefore, it is a complex mountainous landscape, influenced by omnipresent aeolian (wind-driven) erosional processes coming from the Ad-Dahna desert. Minor fluvial (water-driven) erosional process is also present, during abrupt flash floods, which supply groundwater resources, transported by 


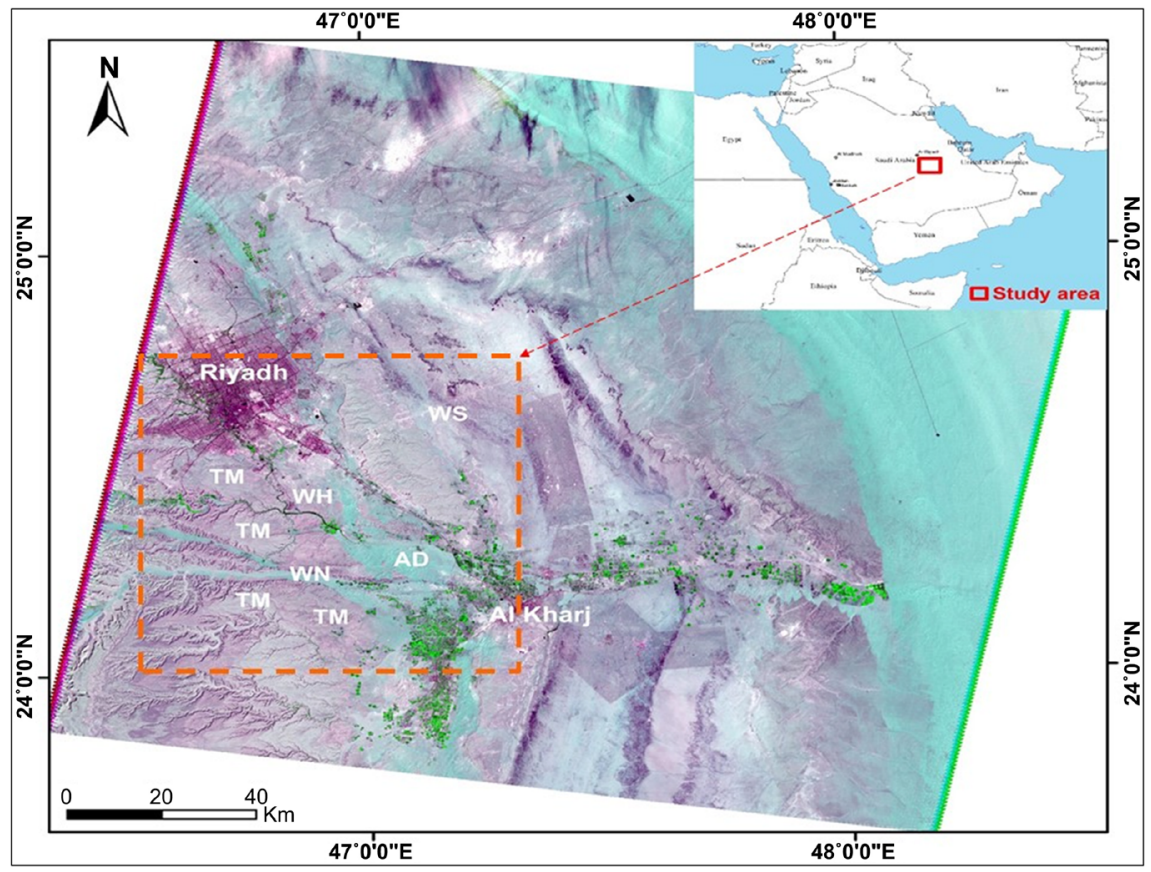

Figure 1. False-colour (1-2-3) ETM+ Landsat imagery (3/4/2006) showing the study area, and main landscapes: Tuwaiq Mountain (TM), Wadi Nisah (WN), Al Khaj Depression (AD), Wadi Hanifah (WH) and Wadi Silay (WS).

the Wadi Nisah-Sahaba grabens into the Al-Kharj oasis. The degree of material removal from the base of the slopes by fluvial and aeolian processes is strongly influences the landscape weathering at different temporal and spatial scales [21].

The landscape morphology of this arid region has evolved through a long period of geological process, geomorphological evolution, and human processes, during both paleo and recent geologic times. Central Arabia, including the southern Riyadh region is currently under arid land conditions where aeolian processes are prevailing, even though it was subjected to a complex morphological landscape evolution. The region underwent significant superposed tectonic and geomorphic events, starting with the deformation of the interior homocline by central arch development and the Alpine-Himalayan orogeny during the late Tertiary. Then, it underwent a late Central Arabian graben system and associated left lateral strike-slip faults during the Quaternary [22]. The Nisah-Sahba trans-tensional fault zone is a large-scale feature that represents the southern boundary of the East Arabian Block (EAB), which is located in the east of Arabia (Figure 2). The $\mathrm{EAB}$ was developed during the late Alpine-Himalayan orogeny after the opening of the Red Sea and separation of Arabian and African plates during the Oligocene, leading to the Arabia/Eurasia collision. Since the middle Pleistocene-Holocene period, rainfall and groundwater level are higher during pluvial phases, developing interstratal and Dinaric karstification of the carbonate- and evaporate-bearing rocks that formed Cenozoic depressions, caves, and sinkholes [1] [23]. From the start of the Holocene to the present, the region has been mainly under aeolian and minor fluvial processes. This long history of 


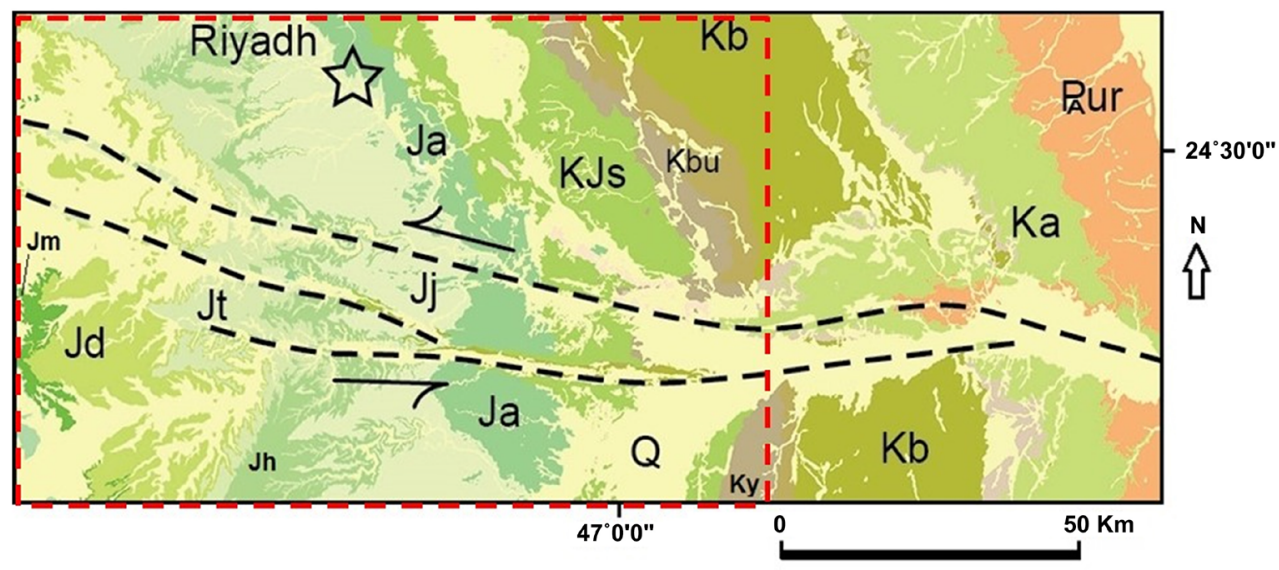

LEGEND

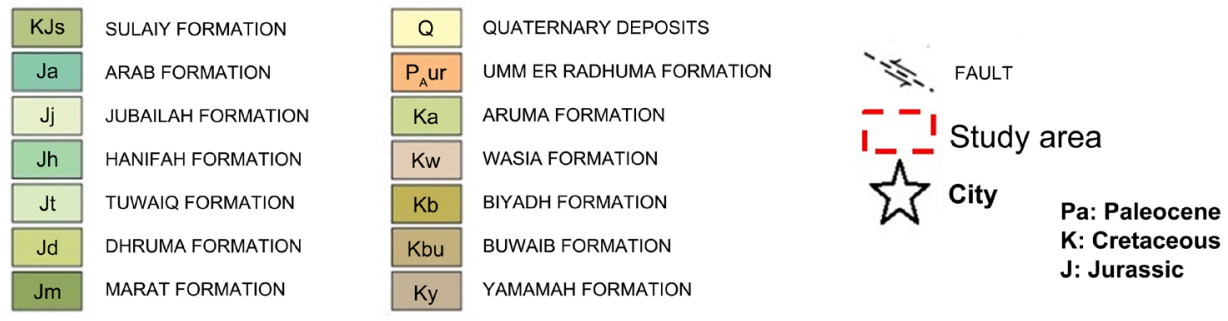

Figure 2. Regional geology map of the study area (adapted from [22]).

deformation and geomorphic development produced attractive arid landform exposures for geotourism, such as the Tuwaiq escarpment, caves and sink holes, and sand dune fields. Anthropogenic activity and urban sprawl are increasingly spreading in all directions from Riyadh [24] and might reach the affected region in the coming years. Therefore, with these underlying ground conditions that might trigger hazards, urban sprawl trends must be established in a balanced and considered manner, creating building plans that guide the urban fabric and determine controls for land use and development of agricultural land between Riyadh and Al-Kharj cities. The Tuwaiq Mountain series (TM) form an overall plateau, cut through by different wadis (Figure 1), such as Wadi Hanifah (WH), which extends from northwest to southeast, and Wadi Al Awsat (WA) and Wadi Nisah (WN), which extend from west to east and empty into a regional depression known as the Al-Kharj Depression (AD). The Wadi Hanifah and Wadi as-Silay (WS) are linear valleys running north to south, whereas Wadi Nisah and Wadi Hanifah run west to east and are originally grabens formed by tectonic events [22] [23]. These wadis cross-cut steep beds between hard and brittle Mesozoic and Cenozoic clastic, carbonate, and evaporitic rocks (Figure 2).

\section{Data and Methods}

To fulfil the abovementioned objectives, the available radar data are acquired; two radar wave components of ERS-1/2 and ENVISAT images are found between 1996 and 2008 (Table 1). Eight amplitude images are produced, multi-dated, calibrated, filtered, georeferenced and orthorectified at a resolution of 20 meters. 
Table 1. Data used ERS-1/2 and ENVISAT.

\begin{tabular}{cccccccccc}
\hline $\mathrm{N}^{\circ}$ & Date & Time of day & Satellite & Orbit & \multicolumn{2}{c}{ Track } & \multicolumn{2}{c}{ Frame Center (Lat/Long) Incidence angle } \\
\hline 1 & $12 / 05 / 1996$ & $07: 27: 37.25$ & ERS-1 & 25230 & 192 & 3123 & $24.36 / 46.56$ & $23.247^{\circ}$ \\
2 & $13 / 05 / 1996$ & $07: 27: 38.92$ & ERS-2 & 05557 & 192 & 3123 & $24.22 / 46.53$ & $23.247^{\circ}$ \\
3 & $29 / 09 / 2003$ & $06: 57: 28.00$ & ENVISAT & 08262 & 192 & 3118 & $24.28 / 46.60$ & $22.931^{\circ}$ \\
4 & $12 / 01 / 2004$ & $06: 57: 27.00$ & ENVISAT & 09765 & 192 & 3123 & $24.26 / 46.59$ & $22.939^{\circ}$ \\
5 & $26 / 04 / 2004$ & $06: 57: 26.00$ & ENVISAT & 11268 & 192 & 3115 & $24.25 / 46.59$ & $22.942^{\circ}$ \\
6 & $31 / 05 / 2004$ & $06: 57: 31.00$ & ENVISAT & 11769 & 192 & 3123 & $24.25 / 46.59$ & $22.929^{\circ}$ \\
7 & $31 / 01 / 2005$ & $06: 57: 26.00$ & ENVISAT & 15276 & 192 & 3120 & $24.25 / 46.59$ & $22.922^{\circ}$ \\
8 & $21 / 01 / 2008$ & $06: 57: 18.00$ & ENVISAT & 30807 & 192 & 3119 & $24.25 / 46.59$ & $22.921^{\circ}$ \\
\hline
\end{tabular}

These images are compared with one another by producing 17 diachronic images of the pairs at different intervals (1996, 2003, 2004, 2005, 2008). The eight Single Look Complex (SLC) images of SAR satellites ERS-1/2 and ENVISAT were processed by pulse compression in the radial direction in distance and by SAR aperture synthesis in the azimuthal direction. In this type of product, each pixel is represented by a complex value (real and imaginary part) from which the amplitude and phase of the signal are extracted. For this study, eight SLC images from the ERS-1/2 and ENVISAT satellites' images have 4904 columns and 29,715/29,708 rows for ERS-1/2 and 5164 columns and 26,172, 27,314, 27,325, $27,315,27,325$, or 27,326 rows for ENVISAT. Radiometric calibration involves bringing the produced image (amplitude, intensity) to a real ground reflectance or radiance. Geo-referencing makes it possible to have the images produced in the same cartographic projection system (UTM zone 38-N, WGS84). This step was carried out automatically by assigning the geographical characteristics of each image. Orthorectification involves correcting the amplitude or intensity image to the shape of the Digital Elevation Models (DEM) from the Shuttle Radar Topography Mission (SRTM) at $30 \mathrm{~m}$ resolution. Filtering is the removal of the speckle effect to increase the readability of an image. The data experienced radiometric calibration, processed by pulse compression in the radial, range, and azimuthal directions. These images used in this study cover an area of $100 \mathrm{~km} \times$ $100 \mathrm{~km}$ with a resolution of $4 \mathrm{~m}$ in azimuth and $20 \mathrm{~m}$ in distance. In this type of product, each pixel is represented by a complex value (real and imaginary parts) from which the signal amplitude and phase are extracted. The acquisition is descending (day). The scene is illuminated to the right in the lateral view with a $23^{\circ}$ angle of incidence in the C-band at a wavelength of $5.65 \mathrm{~cm}$ and with vertical polarisation $(\mathrm{V} / \mathrm{V})$.

The region south of Riyadh using SAR images underwent the application of the derivative of the differential interferometry (DInSAR) technique, the coherence image, which distinguishes stable areas that have retained the phase from non-stable areas that disturb the phase. DEM-SRTM images are used for the arid region south of Riyadh with a resolution of $30 \mathrm{~m}$ to eliminate the influence of 
topography. The choice of the two dates used in the coherence image is based on feasibility conditions; data are considered by temporal baseline interval (Btemp) from one day to 12 years, adopting a spatial baseline of $<1000 \mathrm{~m}$. This study used the GAMMA software, under the Linux and Windows (Cygwin) operating systems, for the realisation of the differential interferograms. The GAMMA software developed by [25] supports the entire processing chain from SAR raw data to end products such as DEM (Digital Elevation Model), displacement maps and land use maps. All the pairs are formed from these data, and the calculated geometric characteristics of the images for each pair are processed (Table 2). The DInSAR was performed using the Centre national d'études spatiales (CNES) method, using two passes and an external DEM. The carried-out treatments of differential interferograms show fringes corresponding to the phase difference. Coherence images demonstrate the reliability of the interferograms producing $(0=$ minimum coherence; $1=$ maximum coherence). Coregistered amplitude images correspond to the realised differential interferograms and unwinding of the realised phase difference. These images are compared with one another by making colour composites at different intervals ranging from one day (24 hours) to 11 years and seven months (1996-2008); the processing steps perform and extract eight calibrated, georeferenced, orthorectified, and filtered amplitude

Table 2. Geometric characteristics of each image tandem ERS-1/2 and ENVISAT. $B_{\text {temp }}$ : Baseline time. $\mathrm{B}_{\text {perp }}$ : Perpendicular baseline Mod_Coh: Modeled coherence. $\mathrm{H}_{\mathrm{am}}$ : Height of ambiguity $\left[\mathrm{h}=\mathrm{H}_{\mathrm{amb}}{ }^{*}\right.$ phase/2ח]. Delta fDC: Doppler baseline.

\begin{tabular}{ccccccc}
\hline \multicolumn{5}{c}{ ERS1/2 } \\
\hline $\mathbf{N}^{\bullet}$ & Dates (Master/Slave) & $\mathbf{B}_{\text {temp }}$ (days) & $\mathbf{B}_{\text {perp }}(\mathrm{m})$ & Mod_Coh & $\mathrm{H}_{\text {amb }}(\mathrm{m})$ & Delta fDC (Hz) \\
\hline 1 & 12 May 1996/13 May 1996 & -1 & -169.96 & 0.68 & 55.66 & 278.56 \\
& & & ENVISAT & & & \\
2 & 26 Apr. 2004/29 Sept. 2003 & 210 & -554.26 & 0.41 & 16.63 & 72.89 \\
3 & 26 Apr. 2004/12 Jan. 2004 & 105 & 280.13 & 0.69 & -32.90 & -4.74 \\
4 & 26 Apr. 2004/31 May. 2004 & -35 & 578.48 & 0.50 & -15.93 & 0.85 \\
5 & 26 Apr. 2004/31 Jan. 2005 & -280 & -37.76 & 0.72 & 244.08 & 4.40 \\
6 & 26 Apr. 2004/21 Jan. 2008 & -1365 & -161.99 & 0.01 & 56.89 & -27.41 \\
7 & 12 Jan. 2004/29 Sept. 2003 & 105 & -830.25 & 0.26 & 11.08 & 77.64 \\
8 & 12 Jan. 2004/31 May 2004 & -140 & 300.80 & 0.65 & -30.58 & 5.59 \\
9 & 12 Jan. 2004/31 Jan. 2005 & -385 & -316.42 & 0.47 & 29.07 & 9.14 \\
10 & 12 Jan. 2004/21 Jan. 2008 & -1470 & -439.45 & 0.01 & 20.93 & -22.67 \\
11 & 31 Jan. 2005/29 Sept. 2003 & 490 & -516.71 & 0.30 & 17.83 & 68.50 \\
12 & 31 Jan. 2005/31 May 2004 & 245 & 615.51 & 0.38 & -14.97 & -3.55 \\
13 & 31 Jan. 2005/21 Jan. 2008 & -1085 & 124.37 & 0.01 & 74.09 & -31.81 \\
14 & 29 Sept. 2003/31 May 2004 & -245 & 1130.84 & 0.04 & -8.16 & -72.05 \\
15 & 29 Sept. 2003/21 Jan. 2008 & -1575 & 392.35 & 0.01 & -23.52 & -100.31 \\
16 & 31 May 2004/21 Jan. 2008 & -1330 & -739.39 & 0.00 & 12.43 & -28.26 \\
\hline
\end{tabular}


images of the study area in the southern region of Riyadh (Figure 3). 17 colour composition pairs are produced for different satellite intervals (ERS and ENVISAT).

These intensity (colour composition) image pairs of the study area are shown in Figure 4. The colour of each pixel of the resulting image is processed by the equation:

$$
c(p)=a(p)[\mathrm{GB}]+b(p)=[\mathrm{R}]
$$

in which $a(p)$ and $b(p)$ represent values depending on the signal strength of the pixel for the oldest and most recent component respectively; thus, pixel appears in Red [R]. Table 3 summarises the results of colour composite enhancements, while Table 4 shows the legend of the low and high signal and the reflected colour. For a pixel appearing in black and in white, signal strength is equal to:

$$
a(p)=0 \text {, and } b(p)=1 \text {; hence } c(p)=[\mathrm{R}]
$$

\begin{tabular}{|c|c|c|c|}
\hline$a / b$ & 0 & $0<\beta<1$ & 1 \\
\hline 0 & Black & & Red \\
\hline $0<\alpha<1$ & \multicolumn{3}{|c|}{ Intermediate colours between light blue and red } \\
\hline 1 & Light blue & & Yellow/white \\
\hline
\end{tabular}

Table 3. Extreme cases of colours resulting from the coloured composition.

Table 4. The following legend shows the key to interpreting colour composition images in Figure 4 and Figure 6.

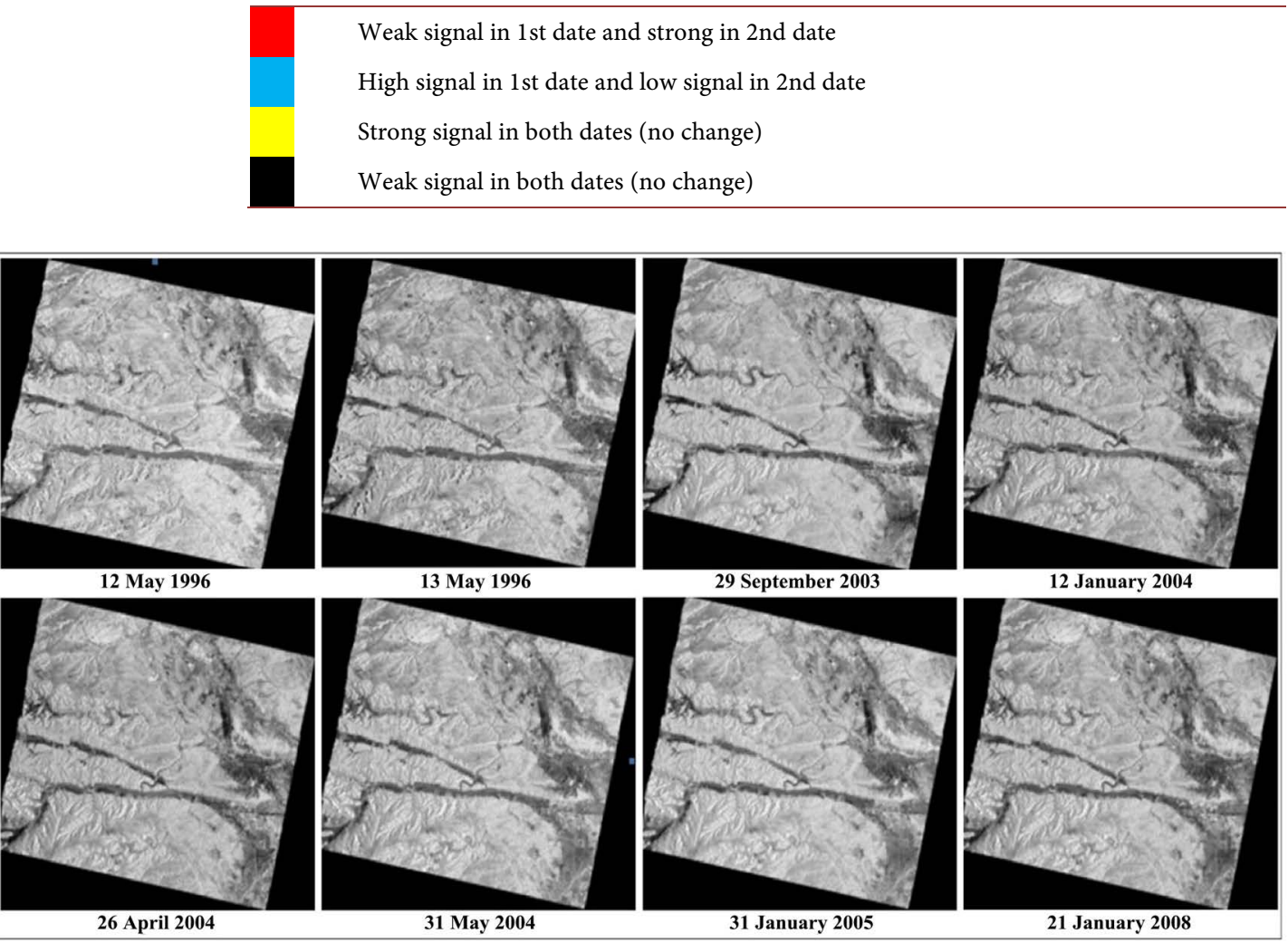

Figure 3. Intensity images of the study area at a resolution of $20 \mathrm{~m}$, calibrated, georeferenced, orthorectified and filtered. 


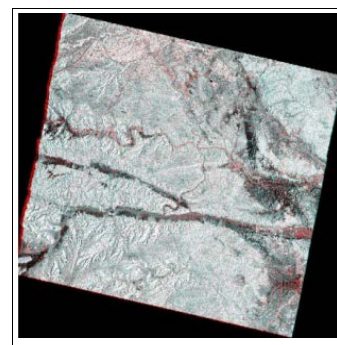

29/9/2003 - 12/1/2004

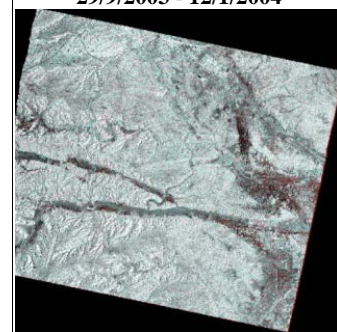

$12 / 1 / 2004$ - 26/4/2004

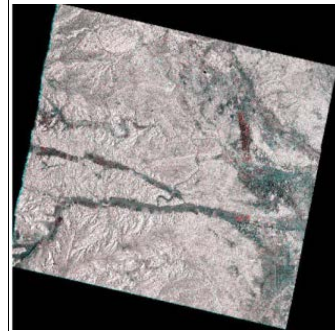

26/4/2004 - 31/1/2005

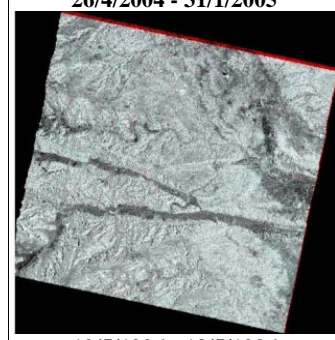

12/5/1996 - 13/5/1996

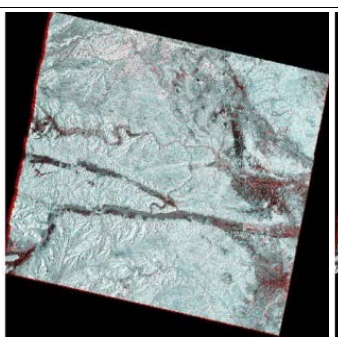

29/9/2003 - 26/4/2004

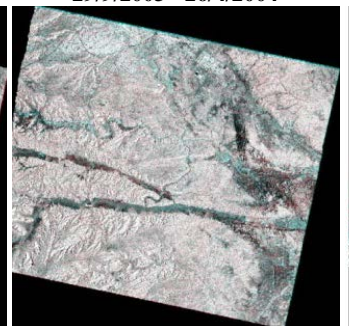

$12 / 1 / 2004-31 / 5 / 2004$

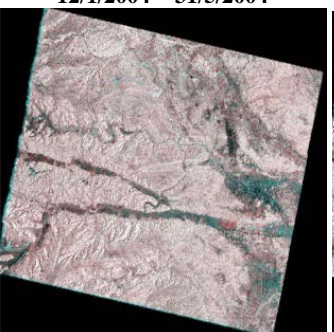

$26 / 4 / 2004$ - 21/1/2008

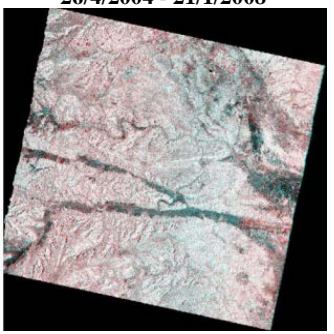

13/5/1996 - 21/1/2008

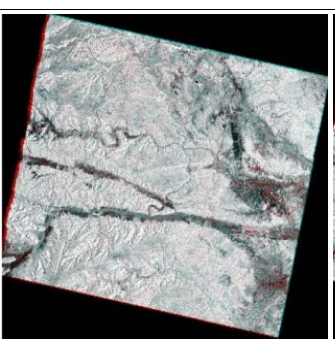

$29 / 9 / 2003$ - 31/5/2004

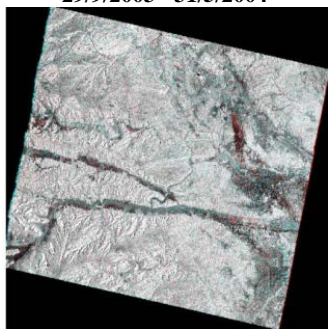

12/1/2004 - 31/1/2005

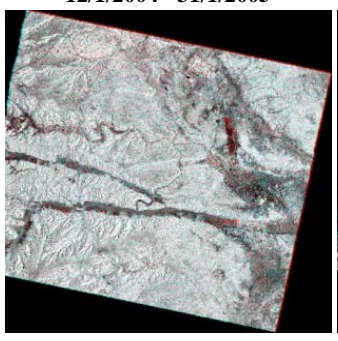

$31 / 5 / 2004$ - 31/1/2005

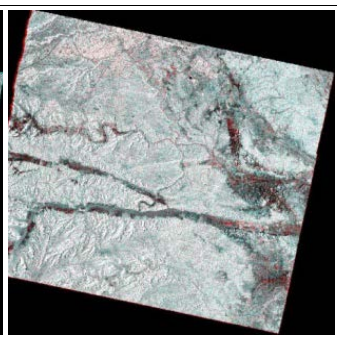

29/9/2003 -31/1/2005

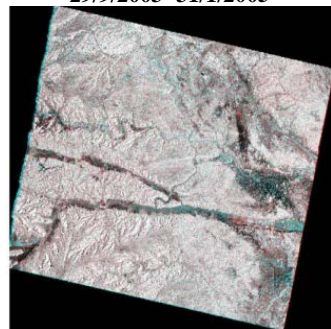

12/1/2004 - 21/1/2008

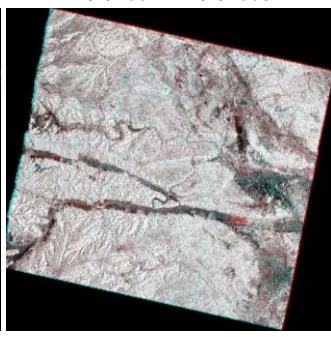

$31 / 5 / 2004$ - 21/1/2008

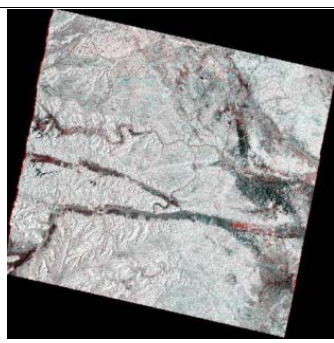

29/9/2003 -21/1/2008

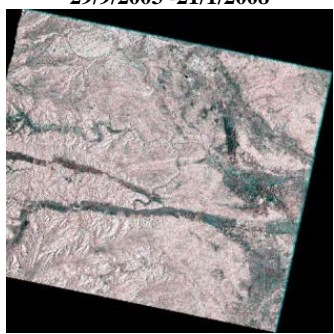

$26 / 4 / 2004$ - 31/5/2004

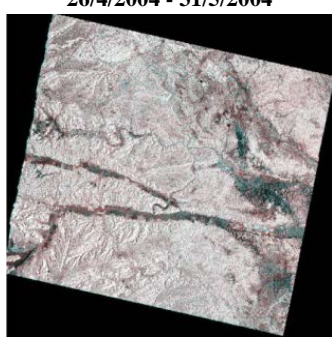

31/1/2005 - 21/1/2008

Figure 4. The colour compositions of calibrated, georeferenced and orthorectified intensity images of the study area at a resolution of $20 \mathrm{~m}(1996-2008)$.

\section{Results}

This section introduces the coming amplitude, intensity, coherence, and interferometric phase imageries results which distinguished the following landscapes: mountainous areas, depressions and grabens, sand dune areas visible on Landsat image (Figure 5), and areas of human activity (urbanisation, roads, and agricultural fields). The radar data have also given rise to several different geomorphological phenomena, such as river captivity and the fragmentation of the surface topography of the plateaus by the grabens and depressions.

\subsection{Amplitude and Intensity Images}

The amplitude illustrates the specificities of the different landscapes of this region, such as the grabens and the Tuwaiq mountain range. It also shows the overlying urban extension of the city of Riyadh towards the deformed areas (Figure 6). 


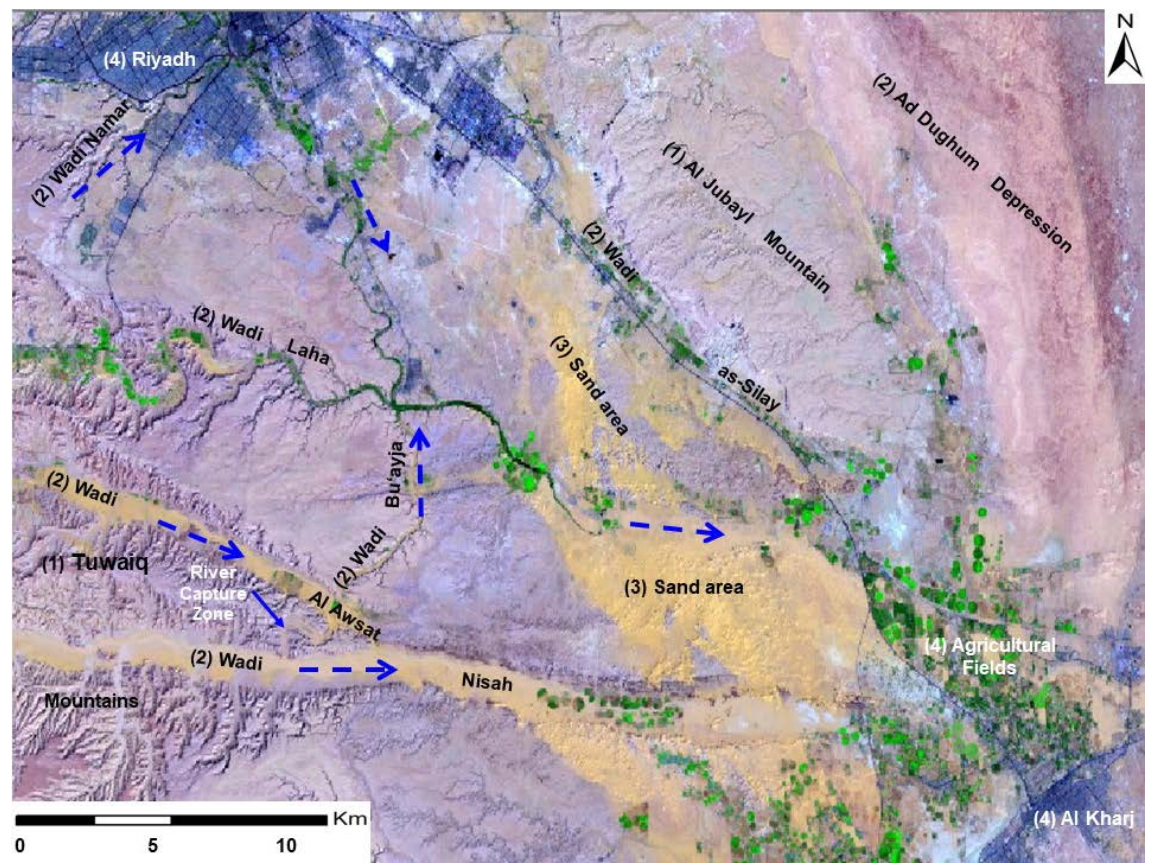

Figure 5. False-colour (2-3-4) ETM+ Landsat imagery for 3/4/2006 showing the development of the new system of hydrology towards $\mathrm{Al} \mathrm{Kharj}$ and the sand dunes areas in the valleys and depressions.

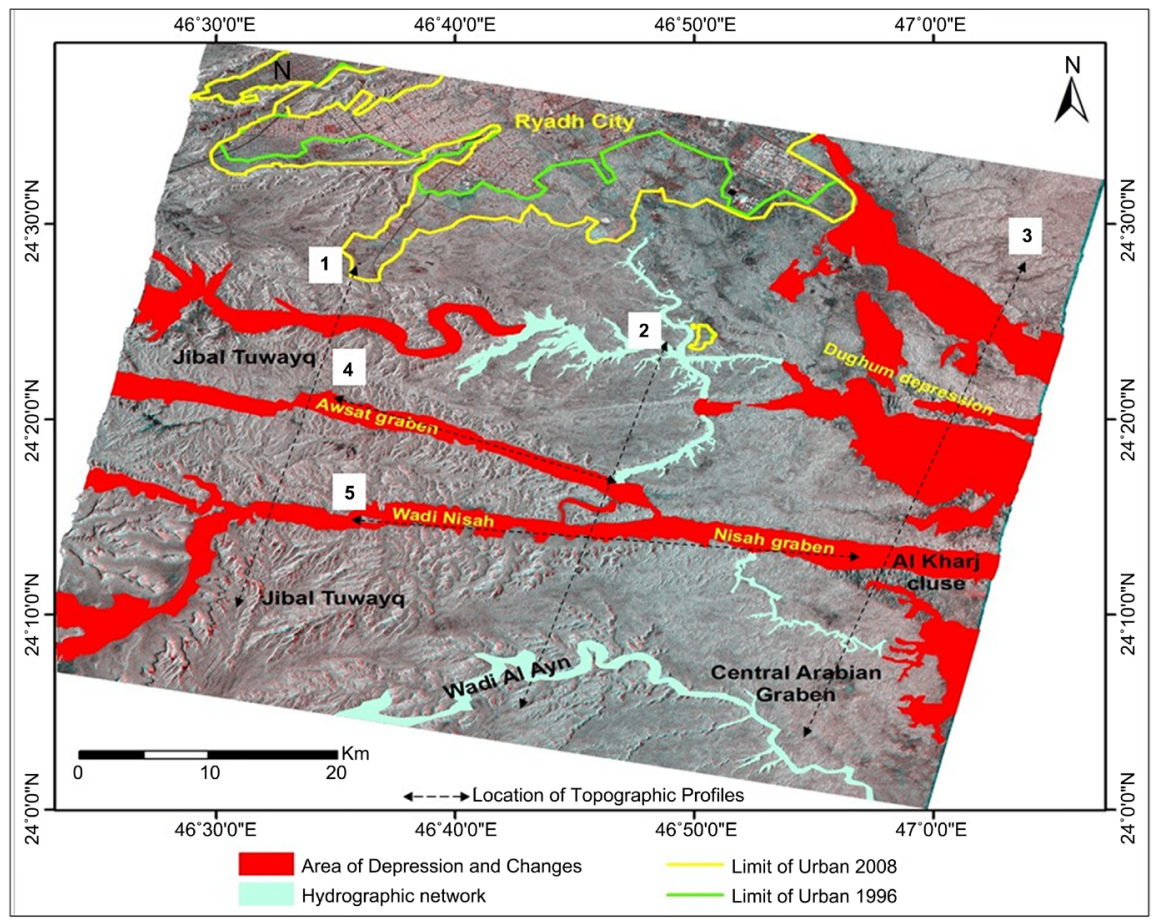

Figure 6. Image intensity 13 May 1996 to 21 Jan. 2008 showing landscape morphology classification of the study area.

This extension is characterised by four directions from the southeast to the southwest, estimated at different rates, related to the encountered complexity of the terrain (Table 5). City limits difference shown in image intensity between 13 
Table 5. Rate of the extension of the city of Riyadh.

\begin{tabular}{ccccc}
\hline \multirow{2}{*}{ Extension direction } & \multicolumn{2}{c}{ UTM Coordinate Centre } & Length & Rate \\
\cline { 2 - 5 } & $\mathrm{X}(\mathrm{m})$ & $\mathrm{Y}(\mathrm{m})$ & $(\mathrm{km})$ & $(\mathrm{km} / \mathrm{an})$ \\
\hline South-East & $695,670.87$ & $2,712,995.17$ & 2.83 & 0.24 \\
South & $679,605.44$ & $2,712,045.97$ & 5.48 & 0.46 \\
South-West & $664,306.42$ & $2,709,481.76$ & 9.23 & 0.77 \\
West-South-West & $652,292.83$ & $2,716,305.38$ & 1.09 & 0.09 \\
\hline
\end{tabular}

May 1996 to 21 Jan. 2008 is used to estimate the extension rate (Figure 6), which is approximately $240 \mathrm{~m} /$ year in the southeast direction; towards the south, this was derived as approximately $460 \mathrm{~m} /$ year; towards the southwest, this rate was approximately $770 \mathrm{~m} /$ year, and towards the west-southwest, it was approximately $90 \mathrm{~m} /$ year. Thus, the total rate of extension is $1560 \mathrm{~m} / \mathrm{year}$, and the average of extension towards the deformed area is $390 \mathrm{~m} /$ year during the 12-year period. N-S profiles 1, 2, and 3 show the variation of the topography from north to south (Figure 7). It shows the effect of the early Quaternary graben system and the consequent late Pleistocene karstifications that deformed the Tuwaiq Mountain series in the study area. The maximum height of elevation is approximately $1000 \mathrm{~m}$ in the west, and the lowest altitude is approximately $400 \mathrm{~m}$ in the east, indicating a maximum $600 \mathrm{~m}$ of downthrown displacement and depression (e.g. [2]). Profiles 4 and 5, plotted E-W along the Awsat and Nisah valleys reveal eastward tilting and consequent capturing of the hydrologic system by the last tectonic event in the Central Arabian graben system (Figure 7). Therefore, a new hydrologic system has developed (e.g. [2] [26]), in which Awsat is pouring into the Nisah that in turn pours into the Sahba valleys west of Al-Kharj City.

\subsection{Differential Interferometry}

The produced coherence image shows the reliability of the performed differential interferogram (Figure 8). In the 280-day period noted above, the southern region of Riyadh showed high coherence values in which the pixel stability suggests high phase values, where disturbed the phase such as vegetation and water shows low coherence values (Figure 8). The image consistency made it possible to distinguish between two parts of the study area. One part retained the signal phase, showing high coherence translated by the Tuwaiq mountain range; in another part, the signal phase was disturbed in e.g. the graben and valleys, indicating low coherence due to unconsolidated sediments, water, and agriculture. The analysis of the landscape south of Riyadh indicates stable terrain with no landslides, subsidence, or flash floods suggested during the period 1996-2008. The realised differential interferogram phase imagery does not indicate displacement fringes nor reactivation of the grabens (Figure 9). The course of this phase difference indicates the atmospheric phase, which correlates with the topography of the region southwest of Riyadh (Figure 9). Altitude values $(x)$ are 

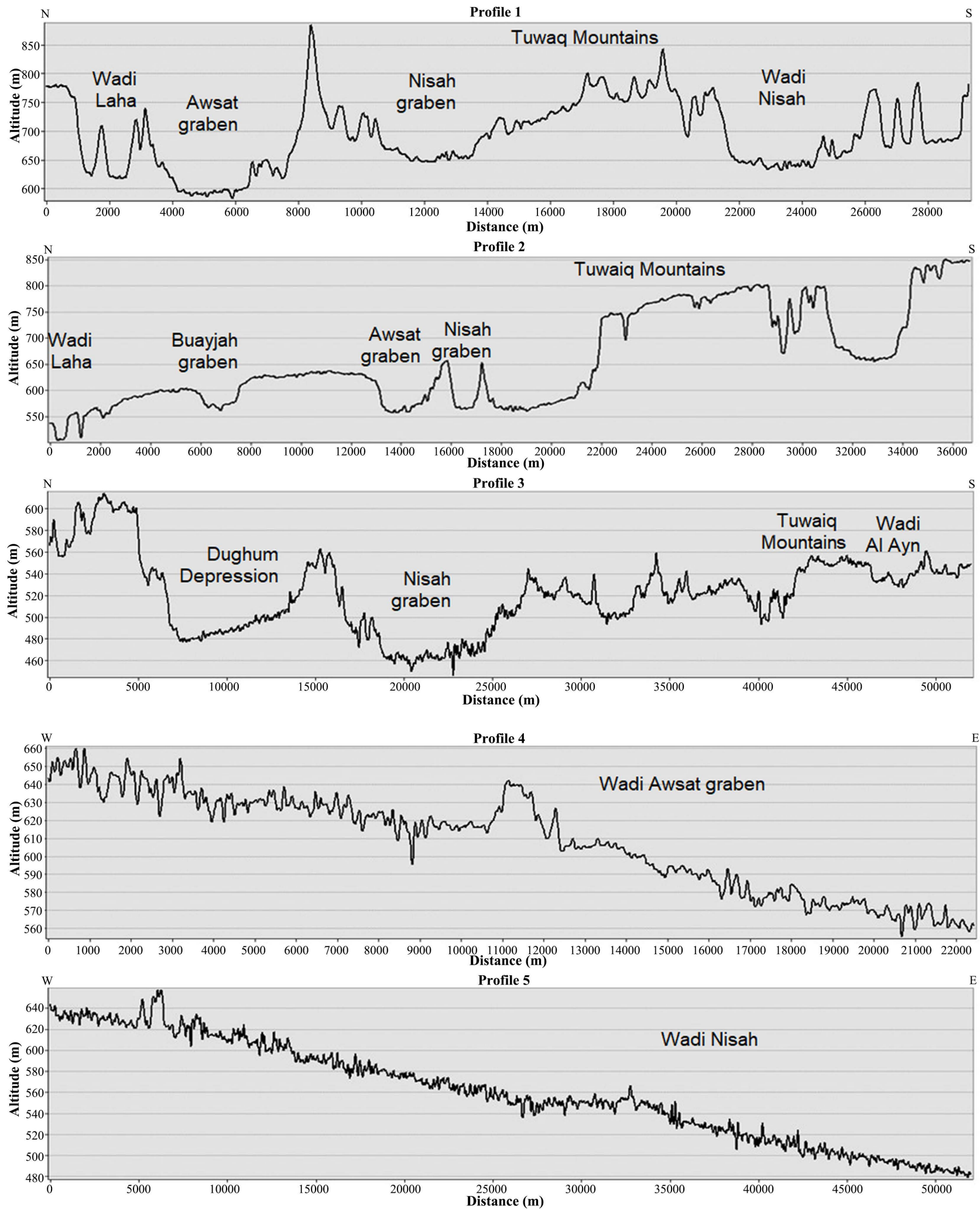

Figure 7. DEM topographic profiles of the intensity image; locations of these profiles are outlined in Figure 6. Profile 1: across the Tuwaiq Mountain, cutting Wadi Laha, Nisah and Awsat grabens, from north to south. Profile 2 across the Tuwaiq Mountain, cutting Wadi Laha, Nisah and Awsat grabens, from north to south. Profile 3: across the Dughum depression and Nisah Graben. Profile 4: along Al Awsat Graben from west to east. Profile 5: along Nisah Graben from west to east. 


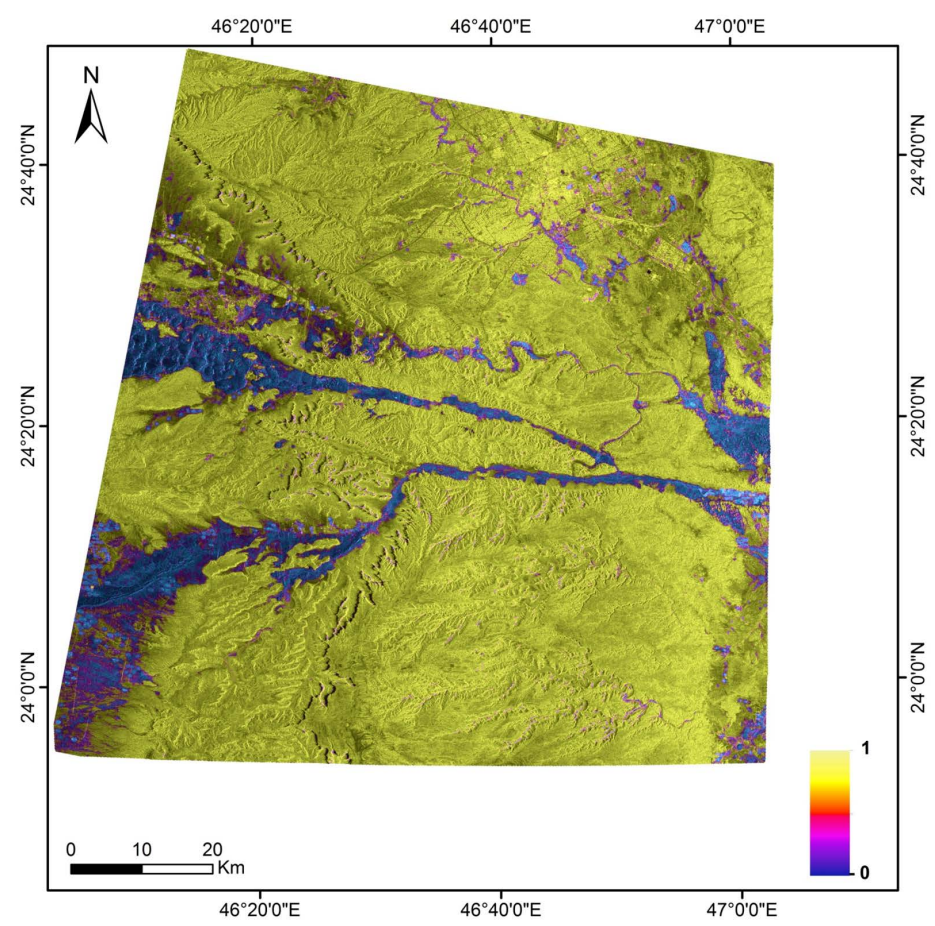

Figure 8. The coherence results of the 26/05/2004 and 31/01/2005 pairs for the southern region of Riyadh (resolution $20 \mathrm{~m}$ ).

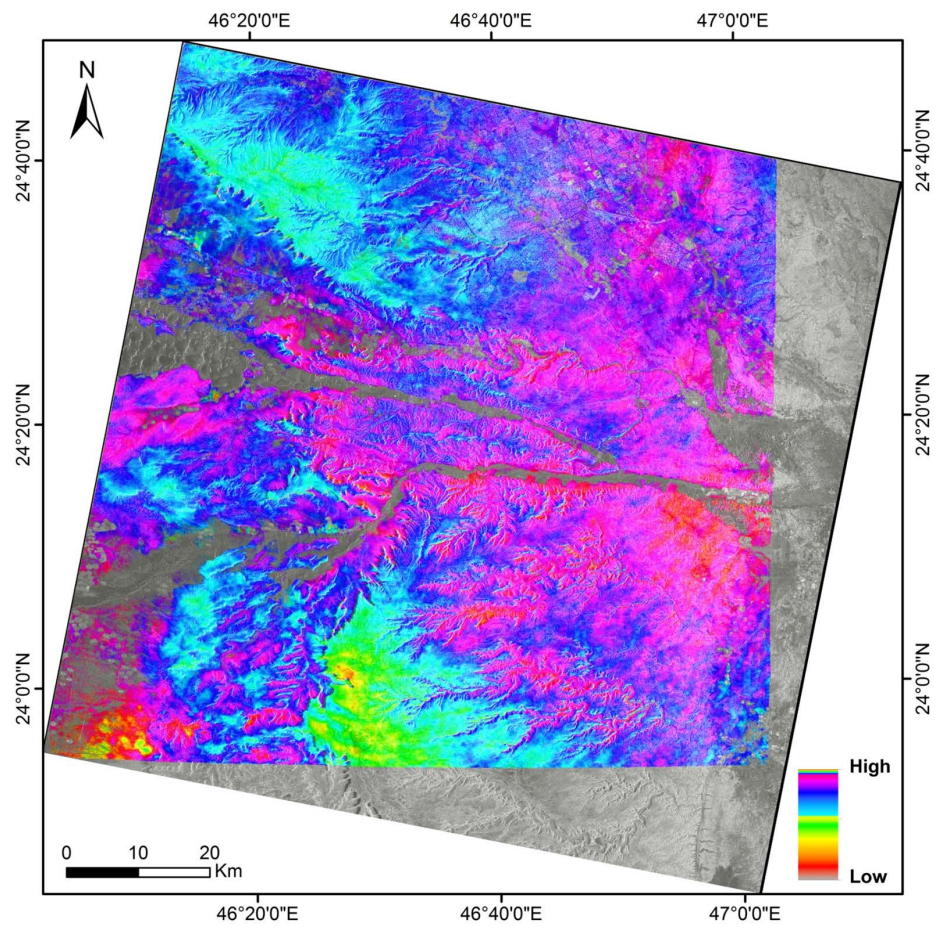

Figure 9. The DInSAR interferometry results of the 26/05/2004 and 31/01/2005 pairs for the southern region of Riyadh (resolution $20 \mathrm{~m}$ ). Altitude values $(x)$ are not provided with a numbered scale for unknown coefficient $(k)$ value in the following equation: $x=$ $2 k \pi$. If $k$ for example is equal to 1 , the lowest altitude value is equal to $2 \pi$. Therefore, the interval of the provided range is equal to $50 \mathrm{~m} /$ colour, ranging from $400 \mathrm{~m}$ to $1000 \mathrm{~m}$ according to the topographic map. 
not provided with a numbered scale for unknown coefficient $(k)$ value in the following equation:

$$
x=2 k \pi \text {. }
$$

If $(k)$ is equal to (1), the lowest altitude value is equal to $(2 \pi)$. Therefore, the interval of the provided range is equal to $50 \mathrm{~m} /$ colour, ranging from $400 \mathrm{~m}$ to $1000 \mathrm{~m}$ according to the topographic map (Figure 9). Figure 10 shows the primary results for the amplitude differential interferometry SAR obtained from the pair of images on 26 May 2004 and 31 Jan. 2005.

\subsection{Diachronic Image Interpretation}

The use of the images dated 29 Sept. 2003, 12 Jan. 2004, and 26 Apr. 2004, and their colour compositions, aimed to enable observation of changes due to the autumn, winter, and spring seasons, which corresponded to the months of acquisition of these three radar images. These images indicate that the observed changes were mainly due to weather conditions. The Jan data indicate a high signal strength, which can be translated into high humidity due to precipitation in the winter of 2004. In 2004, the three data sets dated 12 Jan. 2004, 26 Apr. 2004, and 31 May 2004, corresponding to winter (Jan.) and spring (Apr. and May), and their colour compositions, confirm the origins of changes to rain precipitation.

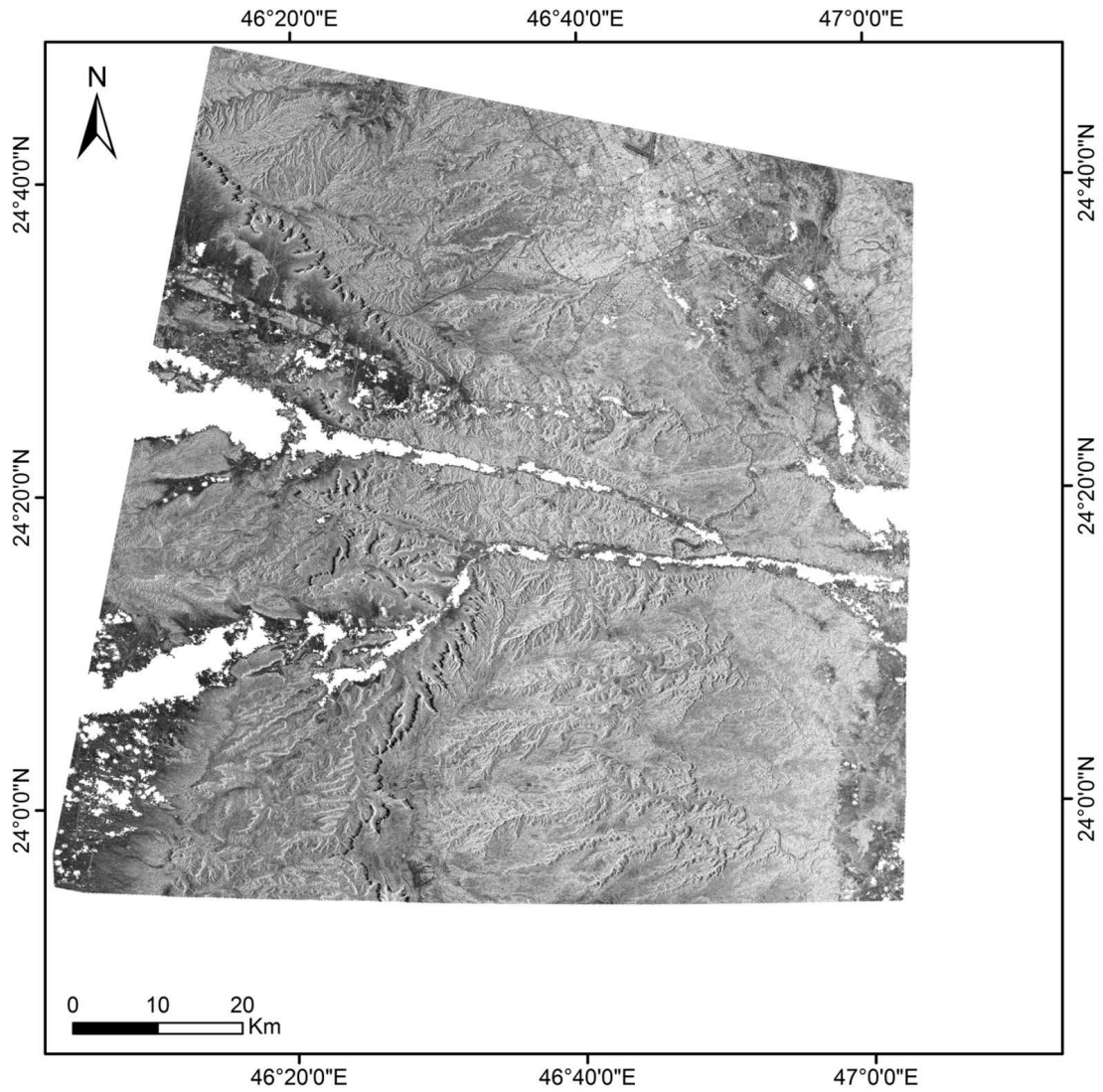

Figure 10. Amplitude differential interferometry SAR results of the 26/05/2004 and $31 / 01 / 2005$ pair from the southern region of Riyadh (resolution $20 \mathrm{~m}$ ). 
This was due to the high signal strength of the 2004 winter season, which was translated into very high humidity compared to the two months of Apr. and May 2004. High intensity indicated by small signal dominance is observed, corresponding to that in the image acquired on 12 Jan. 2004, compared to the two other images acquired on 31 Jan. 2005 and 21 Jan. 2008. This may have been the result of high precipitation observed in this period for 2004 compared with 2005 and 2008 during the same month (Jan.). The changes in these diachronic images were observed in the lowest areas, such as those where wadis and agricultural fields occurred. The mountainous areas (high altitudes) have been preserved due to the low intensity of rainfall recorded during these study periods. Accordingly, it can be stated that this area was morphologically stable during the 12-year period. The irregular slope factor contributed to the transport of carved materials from the highest to the lowest elevation. On the slope surface, several valleys and tributaries (Wadis: Hanifa, Nisah, Al Awsat, Laha) are present, with beds carved out of solid and fragile formations, running eastwards, forming a dense hydrographic network. Various erosion factors, such as wind and water, have contributed to the morphological evolution of the region and the recharging of near-surface aquifers in highly permeable geological formations.

\section{Discussion}

Utility, digital processing, visualisation, and interpretation of radar data (ENVISAT, ERS 1-2) at different dates and the application of differential interference methods, such as interferometric SAR (InSAR), DInSAR, small baseline subset synthetic-aperture radar interferometry (SBAS-InSAR), and pulse-doppler radar (PS), were applied worldwide. Synthetic-aperture radar (SAR) wavelengths and polarisations provide the best results for detecting, identifying, and mapping exposed and buried channels under the sand by detecting reflectance contrast differences between the bed of buried valleys or rivers and the surrounding environment. In arid and semi-arid areas, the amplitude image with a DEM has shown effectiveness in determining soil surface moisture (e.g. [9]). They have their own applications in geological and structural mapping (e.g. [10] [11]). [12]-[17] applied radar data in several countries such as France, Belgium, Romania, Canada, Romania, Vietnam, Mauritania, Morocco and Algeria. Therefore, active remote sensing data are among the important sources for the study and analysis of arid landscape, such as Central Arabia.

SAR is the effective, fast, and inexpensive all-weather operation data of active sensors on board orbital satellites and can be enhanced by several methods, applied in this study. ERS and ENVISAT are two important types of SAR data, which provided valuable information, including major geological structures such as faults, collapses and valleys and detected changes in surface topography. The availability of ERS-1/2 and ENVISAT data at different dates and the contributed two components of the backscattered signal are radiometric energy, which are transmitted and received good signal (amplitude) and time (phase). These data 
rely on the recorded wave distance sent by the radar sensor and the one coming from the target. Amplitude characterises the high-frequency wave images which were used in several landforms and different applications such as in this study, as a substitute for the optical image, reflecting the surface conditions. Stable surfaces are represented by high radiometry values; soft arid surfaces appear with low radiometry values. Therefore, radiometric corrections are very important before image visualisation and interpretation. Moreover, the diachronic analysis of these data highlighted surface variations, particularly in the recent river system, tectonic depressions, agricultural fields, and urban areas, especially by combining them with DEMs which suggest the direction of surface water movement in the region accurately. Diachronic DInSAR images draped over SRTM images are the most suitable data to detect and monitor potentially risk areas, discriminated them as accurately as possible, and estimated the resulting landscape changes.

The Sahba fault cuts through the biggest inland oil field (known as the Gawar oil field) and the Quaternary sand dunes, reaching the Arabian Gulf and connecting with the Zagros Mountain thrust belt. Also, with other regional Wadi Al Batin and Az-Zulfi faults forming a regional feature within Arabia, the East Arabian Block holds most of the oil and gas fields in the world (e.g. [2] [22]. Therefore, this study is conducted based on three factors. Firstly, there is the importance for the people of the oasis, built thousands of years ago for its mild weather, good resources of water, and agriculture, which are essential elements for living humans and animals. Secondly, the reported karstification, fault activities and the extensional geomorphology might have the potential for hazards, especially if triggered by artificial activities and expansion of the nearby cities. Finally, the study area for the surrounding oil and gas fields has its place in the economy. Moreover, this study also investigates whether a reactivation of the faults and grabens by oil and groundwater extraction in the monitored 12 years period is present.

\section{Conclusion}

This study is a regional and remote sensing investigation of the morphology of an arid region. It is possible to clearly distinguish the different aspects that characterise the area. Multi-temporal analysis, conducted using amplitude images, has shown the possibility of mapping surface changes at different dates. It also shows the ability to determine and locate faults, fractures, and other geological features. It makes it possible to understand the evolution of drainage networks over different periods. These radar images address the major issue of urban sprawl, which must be reviewed and planned in a preventive manner. This research can serve as a tool for city planners and decision-makers to prepare future projects for the benefit of the environment and society. Finally, this study contributes to the development of methodologies in similar conditions, including spatial and temporal identification of areas potentially exposed to natural ha- 
zards. This study recommends preserving the region of Wadi Nisah as a national geopark by the Ministry of Environment, Water and Agriculture for several reasons. In this way, all municipalities would take this area out of plans for making new residential areas to expand the two cities of Riyadh and Al-Kharj. The study area has the potential for groundwater, oil, and gas resources. The second potential is the faults' and grabens' reactivations. The third potential is that, as an oasis that has been built thousands of years ago, it can be preserved for long-standing food supply and therefore food safety. This study also recommends sustaining the groundwater for water safety by changing the type and style of irrigated farms to another style that consumes less groundwater.

\section{Acknowledgements}

This project was funded by the Deanship of Scientific Research (DSR) at King Abdulaziz University, Jeddah, under grant No. G-589-125-1438. The authors, therefore, acknowledge with thanks to DSR for technical and financial support.

\section{Conflicts of Interest}

The authors declare no conflicts of interest regarding the publication of this paper.

\section{References}

[1] Bamousa, A.O., Memesh, A. and Dini, S. (2014) Morphostructural Evolution of Ath Thumamah Depression, North Riyadh, Saudi Arabia. Carbonates and Evaporites, 29, 65-72. https://doi.org/10.1007/s13146-013-0173-2

[2] Weijermars, R. (1998) Plio-Quaternary Movement of the East Arabian Block. GeoArabia, 3, 509-540.

[3] Al-Hinai, K.G., Dabbagh, A.E., Gardner, W.C., Khan, A.K., Asif, M. and Saner, S. (1997) Shuttle Imaging Radar: Views of Some Geological Features in the Arabian Peninsula. GeoArabia, 2, 165-178.

[4] Dabbagh, A.E., Al-Hinai, K.G. and Khan, M.A. (1997) Detection of Sand-Covered Geologic Features in the Arabian Peninsula Using SIR-C/X-SAR Data. Remote Sensing of Environment, 59, 375-382. https://doi.org/10.1016/S0034-4257(96)00160-5

[5] Alsalman, A.S. (2010) Interpretation of Radarsat-1 SAR Imagery of Riyadh for Mapping Applications. Journal of King Saud University-Engineering Sciences, 22, 89-98. https://doi.org/10.1016/S1018-3639(18)30496-3

[6] Abdelkareem, M., Bamousa, A.O., Hamimi, Z. and Kamal El-Din, G. (2020) Multispectral and RADAR Images Integration for Geologic, Geomorphic, and Structural Investigation in Southwestern Arabian Shield, Al Qunfudhah Area, Saudi Arabia. Journal of Taibah University for Science, 14, 383-401. https://doi.org/10.1080/16583655.2020.1741957

[7] Abdelkareem, M., Gaber, A., Abdalla, F. and Kamal El-Din, G. (2020) Use of Optical and Radar Remote Sensing Satellites for Identifying and Monitoring Active/Inactive Landforms in the Driest Desert in Saudi Arabia. Geomorphology, 362, Article ID: 107197. https://doi.org/10.1016/j.geomorph.2020.107197

[8] Zhou, X., Chang, N. and Li, S. (2009) Applications of SAR Interferometry in Earth 
and Environmental Science Research. Sensors, 9, 1876-1912. https://doi.org/10.3390/s90301876

[9] Troufleau, D., Audoin, A., Vidal, A., Moran, M.S., Goodrich, D.C. and Washburn, J. (1994) Importance des corrections radiométriques dues au relief pour les données SAR du satellite ERS-1: Applications a l'hydrologie. Xème journées hydrologiques, Orstom, 635-650.

[10] Singhroy, V. and Saint-Jean, R. (1999) Effects of Relief on the Selection of RADARSAT-1 Incidence Angle for Geological Applications. Canadian Journal of Remote Sensing, 25, 211-217. https://doi.org/10.1080/07038992.1999.10874720

[11] Wade, S., Ndoye, A. and Mbaye, M. (2001) Fusion d'images optique et radar: Application a la cartographie du massif granitique de Bambadji (Faleme, Sénégal oriental). Télédétection, 2, 119-127.

[12] Hachemi, K., Abdellaoui, A., Ozer, A., Grecu, F. and Visan, G. (2009) Apport de l'imagerie radar SAR (Images d'Amplitude) pour l'analyse du changement dans la région de Buzau (Roumanie). Revista de Geomorfologie, 11, 63-72.

[13] Hachemi, K., Abdellaoui, A., Grecu, F., Ozer, A. and Visan, M. (2010) Association d'images diachroniques avec un MNA pour une meilleure interprétation des changements de paysage dans la région de Buzau (Roumanie). Revista de Geomorfologie, 12, 53-65.

[14] Hachemi, K. and Thomas, Y.F. (2013) Analyse de la mobilité d'un champ de Barkhanes (Mauritanie) à partir des images SAR. Conférence internationale de Géomatique et d Analyse Spatiale SAGEO (Spatial Analysis and GEOmatics), European Institute for Marine Studies, Brest 23-26 September, 273-286.

[15] Hachemi, K., Thomas, Y.F., Senhoury, A.O.M., Achek-Youcef, M., Ozer, A. and Nouacer, H.A. (2014) Etude de l'évolution du trait de côte au niveau du port de Nouakchott (Mauritanie) à partir d'une chronique d'images SAR d'ENVISAT, Revue Internationale de Géologie, de Géographie et d'Ecologie Tropicales, Geo-Eco-Trop., No. 38, Tome 1, n.s. 169-178.

https://geoecotrop.be/uploads/publications/pub_381_15.pdf

[16] Hachemi, K., Visan, M., Ozer, A., Grecu, F., Anouche, K., Jurchescu, M. and Nouacer, M. (2014) The Interest of Coherence from Radar SAR Images in the Follow-up of Urban Extensions of Focsani City (Romania). Geoinformatics and Geostatistics: An Overview, 1, 1-15.

[17] Hachemi, K., Thomas, Y.F., Senhoury, A.O.E.-M. and Martin, T. (2015) Multitemporal Analysis of the City of Nouakchott (Mauritania) Based on ENVISAT ASAR Images. Geoinformatics \& Geostatistics. An Overview, 4, 1. https://doi.org/10.4172/2327-4581.1000129

[18] Hachemi, K., Amrouni, Y., Daoudi, M. and Bamousa, A.O. (2020) Diachronic Study of the Great Sebkha of Oran (Western Algeria) Based on SAR Radar Images (1992-2011). Journal of Taibah University for Science, 14, 1433-1446. https://doi.org/10.1080/16583655.2020.1825183

[19] Burgmann, R., Rosen, P.A. and Fielding, E.J. (2000) Synthetic Aperture Radar Interferometry to Measure Earth's Surface Topography and Its Deformation. Annual Review of Earth and Planetary Sciences, 28, 169-209. https://doi.org/10.1146/annurev.earth.28.1.169

[20] Gamo, M., Shinoda, M. and Maeda, T. (2013) Classification of Arid Lands, Including Soil Degradation and Irrigated Areas, Based on Vegetation and Aridity Indices. International Journal of Remote Sensing, 34, 6701-6722. https://doi.org/10.1080/01431161.2013.805281 
[21] Migon, P. (2010) Geomorphological Landscapes of the World. Springer, Dordrecht. https://doi.org/10.1007/978-90-481-3055-9

[22] Bamousa, A.O., Memesh, A.M., Dini, S.M. and Al-Zahrani, A.A. (2017) Tectonic Style and Structural Features of Alpine-Himalayan Orogeny in Central Arabia. In: Roure, F., Amin, A., Khomsi, S. and Al Garni, M., Eds., Lithosphere Dynamics and Sedimentary Basins of the Arabian Plate and Surrounding Areas, Frontiers in Earth Sciences, Springer, Cham, 173-185. https://doi.org/10.1007/978-3-319-44726-1_8

[23] Bamousa, A.O. (2018) Tectono-Geomorphic Development of Intra-Continental Cenozoic Depressions within Cretaceous Rocks of the Interior Homocline, Central Arabia. Arabian Journal of Geosciences, 11, Article No. 562. https://doi.org/10.1007/s12517-018-3884-9

[24] Altuwaijri, H., Alotaibi, M., Almudlaj, A. and Almalki, F. (2018) Urban Extension of the City of Riyadh (1987-2017) Using Remote Sensing and GIS Techniques. Architecture and Planning Journal, 30, 195-213, Riyadh, Saudi Arabia (in Arabic). https://cap.ksu.edu.sa/sites/cap.ksu.edu.sa/files/attach/jap_ksu_jul2018_ar2.pdf.

[25] Werner, C., Wegmueller, U., Strozzi, T. and Wiesmann, A. (2000) GAMMA SAR and Interferometric Processing Software. ERS - ENVISAT Symposium, Gothenburg, 16-20 October.

[26] Bamousa, A.O., Daoudi, M. and Hachemi, K. (2020) Tectono-Geomorphic Development of an Active Transtensional Depression: A Case Study of Mountain Tuwaiq Plateau, South Riyadh City, Saudi Arabia. Carbonates and Evaporites, 35, Article No. 127. https://doi.org/10.1007/s13146-020-00658-6 